\title{
Long Term Fuel Sustainable Fission Energy Perspective Relevant for Combating Climate Change
}

\author{
Vladimir Knapp ${ }^{1}$, Mario Matijević ${ }^{1}$, Dubravko Pevec ${ }^{1}$, Boris Crnobrnja ${ }^{1}$ and Dinka Lale ${ }^{2}$ \\ 1. Faculty of Electrical Engineering and Computing, University of Zagreb, Unska 3, 10000 Zagreb, Croatia \\ 2. Department of Electrical Engineering and Computing, University of Dubrovnik, Cira Carića 4, 20000 Dubrovnik, Croatia
}

Received: July 26, 2016 / Accepted: August 10, 2016 / Published: November 30, 2016.

\begin{abstract}
A climate relevant and immediately available proven light water nuclear strategy with a potential to contribute essentially and timely to reduction of carbon dioxide emission to the year 2065 was assumed. The perspective of fission energy after that year is considered. Two technologies with long term perspective which need no or small amounts of uranium, i.e. fast breeders and molten salt thorium reactors were singled out. The main technical and safety characteristics were considered. In both of these technologies it is essential to have starter nuclides as neither U238 nor Th232 are fissile. It was investigated whether plutonium from spent fuel of light water reactors generated to the year 2065 would be present in quantities sufficient to continue operation on the same or similar level in both technologies. However, taking into account operational safety, proliferation risks, and waste production preference must be given to thorium technology.
\end{abstract}

Key words: Uranium and plutonium requirements, fast breeder reactors, molten salt thorium reactors, climate change.

\section{Introduction}

Our recent proposal [1] to replace coal power plants with nuclear power plants of current design was dictated with immediate climate problems requiring immediate intervention and solution proposed was possible with available and proven technology. We selected light water reactor technology with longest uninterrupted operational experience, and specified PWR reactors a representative in this technology. Our earlier study [2] of the potential of this technology to contribute essentially to carbon emission has shown that large reduction of carbon emission can be achieved, more than one third of the reduction needed to keep global temperature rise below $2{ }^{\circ} \mathrm{C}$, with assumption that all uranium resources estimated in all categories at 17.1 Mt [3] be consumed in open fuel cycle without reprocessing. In our later analysis of uranium resources [4], we estimated uranium perspective in future 50

Corresponding author: Dubravko Pevec, Ph.D., professor, research fields: nuclear engineering, energy engineering. years on the basis of geological arguments. Therefore, we expect that exploration in hitherto relatively unexplored regions should bring uranium resources in acceptable cost range to 20-25 Mt. Based on these estimates and the information on progress or absence of progress in nuclear fusion and CCS (carbon capture and sequestration), we feel that nuclear fission deserves fresh look in the light of new developments in nuclear technologies. Our proposal to replace all CPP (carbon power plants) in the 40 years between 2025 and 2065 was intended to remove the worst emitters of $\mathrm{CO}_{2}$. That nuclear strategy would require construction of 1,600 GW of LWR (light water reactors) reactors additional to $500 \mathrm{GW}$ of estimated nuclear power in operation by 2025. Cumulative uranium consumption from 2016 through 2025 and 2065 including until 2105 operation of outgoing reactors completing 40 years of lifetime, would amount to $15 \mathrm{Mt}$. In case of 60 years of lifetime last reactor built in the 2025-2065 period would retire by 2125 . Cumulative consumption in that case would reach $22 \mathrm{Mt}$. Consequently, after these figures on 
cumulative uranium consumption we cannot assume further production of fission energy in conventional thermal reactors. But by assumption of non-processing of spent fuel reservation of future options has been incorporated in a proposal to replace all coal power plants. Assumption of no reprocessing of spent fuel was aimed at giving some 50 years to develop reliable international controls of proliferation sensitive materials. In the same time plutonium in spent fuel is the valuable material necessary when fission energy beyond existing reserves of uranium is contemplated. Two technologies that can provide long term nuclear fission energy on the large scale with little or no demand on uranium, provided that plutonium is available, are FBR (fast breeder reactors) and MSTR (molten salt thorium reactors). We should understand that a prior production of plutonium, such as in proposed nuclear build up for replacement of CPP, is essential prerequisite to long term contribution of nuclear fission energy for reduction of carbon emission. On the other hand, when initial plutonium charges are supplied, the road is open to very large production of fission energy. In what follows we take a look on the prospects of these two technologies for long term production of fission energy. In this we abstain from predictions on nuclear fusion after 2065, or other new energy technologies we do not know yet. Our intention is to judge whether any or both of these fission technologies have the potential for long term and large scale production of fission energy. The word potential here is used in wider range of nuclear technology characteristics, relating to reactor safety, fuel transport and manipulation, amount of radioactive waste, proliferation risks and economy. Cheap uranium from the sea, economic CCS installations, or the cheap fusion energy, perhaps with fission-fusion hybrids, could change the motivation to develop fission only energy. But the point of this study is to assess the perspective of fission energy should these alternatives fail, technically or economically, or should not be in time for climate change mitigation.

\section{The Fast Breeder Reactors as a Long Term Perspective}

One possibility high on the list of future nuclear technologies is the so called FBR (fast breeder reactors), reactors fuelled with mixture of uranium 238 and plutonium, converting uranium 238 into plutonium 239 , which is a fissile nuclide, produced with addition of other less abundant isotopes. Plutonium is bred in a fertile blanket around the reactor core containing a mixture of uranium 238 and plutonium. If the amount of produced plutonium in the blanket and the core is sufficient to replace fissile plutonium isotopes consumed by reactor operation, reactor is called breeder. The plutonium extraction from fertile blanket requires repeated processing in separate processing installations. Transport of irradiated uranium containing fissile isotopes to processing installation and of separated plutonium to breeder reactors would be high security operations. Those breeder reactors, that have been built, use sodium as coolant. The sodium as coolant has attractive nuclear properties and is well suited for high power densities in a small reactor core without moderator. However, the sodium is chemically very reactive and coolant leaks are consequently very dangerous. New developments are aiming to replace the sodium with, from safety view, more acceptable candidates, such as beryllium, lead or mixtures of these. The reactor core without moderator resulting in very high power density requires small diameter fuel. The resulting sensitivity to change of fuel geometry as a consequence is another weak point of these reactors. Very important characteristic of breeder reactor is its doubling time, essentially the time to produce amount of plutonium to launch another reactor of the same type. Unfortunately, most of the measures to increase safety of breeder reactor tend to lengthen doubling time. Quantitative results with new types of coolants could be very important for a long term perspective. Several such sodium cooled fast reactors have been constructed, largest of them in France, Super-Phoenix, with power of 1,200 MW, in 
operation from 1984 to 1998 , intended to be the last step to commercial reactor. With such technical and safety characteristics we do not see fast breeder reactors as very desirable future technology for long term nuclear development. Looking at its shorter term prospects, it is very important to note that existence of one or few breeder reactors that could be built, or are built, with presently available plutonium, in the period prior to 2065 cannot be a base to talk about climate relevant strategy based on fast breeders. There is no practical vision how to produce plutonium necessary to continue production of fission energy on the scale of some $2,000 \mathrm{GW}$ by 2065 , except by operation of a large number of thermal reactors. Without a large number of thermal reactors to produce plutonium there would not be enough plutonium to launch climate relevant build up of fast breeders. Our proposed strategy of CPP replacement [1] lasting till 2065 with exiting operations until 2105 would produce 15,392 t of plutonium, and 22,015 $\mathrm{t}$ with extended lifetime of 60 years and operations till 2125. If we want to continue climate change relevant nuclear build-up by introducing fast breeders after 2065, we should compare the plutonium required for launching with the quantity of plutonium produced in thermal reactors operated prior to about 2065. If for the sake of definiteness and quantification we stay with the proposal of CPP replacement strategy by 2065 and in next 40 years, respectively 60 years of operation of outgoing LWR reactors with production of 15,392 t, respectively $22,015 \mathrm{t}$ of plutonium, we can estimate the number of FBR that could be launched.

Recent survey of breeder research and development dating from fifties to 2012 is given in Ref. [5]. It is a long story of brilliant idea backed by strong motivation of much more efficient use of uranium that was seen as limiting energy resource. In the passing decades techno-political issues related to nuclear proliferation have gained importance. There is no vision of international inspection and control system to assure proliferation safety for operation of some 1,600 or more FBR reactors distributed over many countries, requiring frequent supply of plutonium, and return of used fuel to reprocessing installations.

\section{The Molten Salt Thorium Reactors as a Long Term Option}

We have selected MSTR as re-emerging technology for consideration as an alternative to fast breeders to operate after the year 2065. Whilst FBR reactors benefit from the high neutron yield per fission of plutonium 239 with fast neutrons, MSTR take advantage of fission in thermal region where the U233 has the largest neutron yield. Moderation is thus necessary part of the fission process. Both technologies have, in principle, long, practically unlimited future, one based on burning thorium and other on burning uranium 238. Renewed interest in MSTR technology is based on the very important characteristics; on primary circuit at low or atmospheric pressure, on no need for fuel manufacturing, on liquid fuel which allows burning of created U233 without the need of reprocessing the fuel, and the efficient use of abundant thorium. Liquid fuel free of radiation damage allows fuel control and management with on line removal of neutron absorbing fission products.

Examination of the literature concerning the radiotoxicity of thorium fuel cycle, as compared to standard uranium/plutonium fuel cycle, reveals disparities. On one hand, there are papers (mainly qualitative and without supporting details) concluding that the radiotoxicity of thorium fuel cycle is significantly lower than the radiotoxicity of uranium/plutonium fuel cycle [6,7]. On the other hand, some papers contain calculated results that indicate thorium-based spent nuclear fuel radiotoxicity is lower than uranium-based spent nuclear fuel radiotoxicity at decay times ranging from several thousand years to 20,000 years but higher than uranium-based spent nuclear fuel radiotoxicity at longer decay times $[8,9]$. The overall conclusion of the most recent study on this problem [10] is that the radiotoxicity of thorium-based 
fuels containing U233 or plutonium fissile materials is similar to the radiotoxicity of uranium-based fuels containing U235 or plutonium fissile materials but that within this overall similarity there are significant differences in radiotoxicity in specific eras during decay.

Whilst it is the fact that MSTR have little operation experience and will require some technical and technological development, one should be confident that there is enough time to have the MSTR technology ready for large scale constructions by 2065 . Our confidence is based on the determined Chinese development program and on American-Chinese cooperation. We are also confident that the magnitude of the climate problem will stimulate world cooperation on this technology neglecting political and other differences in face of a global climate disaster. Liquid fuel thorium reactor is one of the Generation 4 reactor systems. It is a reactor with a long history. First MSTR was built in Oak Ridge National Laboratory under A. Weinberg, went critical in 1965 and operated successfully until 1969 [11]. No basic problem was identified, corrosion resistant materials were developed. Most of these advantages were recognized in early years but work on MSTR technology was terminated at that time by government decision to concentrate on and fund solid fuel sodium cooled fast breeder reactor. In those Cold War years important factor was a plutonium production. Operation of early MSTR reactor resolved many technical issues. Reactor could operate as a thermal breeder thanks to nuclear properties of U233. However, due to a decision to develop solid fuel light water reactors for nuclear propulsion already in late forties, with first nuclear submarine Nautilus reaching duty in 1955, accumulated experience with light water reactors with solid fuel became a dominating reactor technology. All the same, many nuclear experts after decades of experience with light water reactors point to the advantages of MSTR. One of the points is safety. MSTR operate at atmospheric pressure which is an advantage that cannot be overestimated. Core melting accidents are of course impossible. MSTR are not in danger from coolant fire as the present sodium cooled breeder reactors. Dramatic escape of coolant is impossible. Simple measures exist to prevent overheating of fuel. This can much reduce the costs. Once launched by initial fissile charge MSTR continue to operate on the U233 produced from fertile thorium with addition of thorium only, so no more uranium would be required. Operationally this is an advantage over FBR. Online chemistry with liquid fuel removes neutrons absorbing fission products leaving produced U233 as new fuel. Permanent removal of fission products from the molten fuel is one of the reactor features that make possible very high utilization of thorium. Liquid form of fuel avoids radiation effects that limit the fuel burn-up in solid fuel. Once MSTR are launched, annual addition of natural thorium is needed only on the level of about one ton for reactor electric power of $1 \mathrm{GW}$ [12]. A general non-technical overlook on the advantages of MSTR is given by Ref. [13]. A very important strategic and political advantage can be noted. Long term reliance on uranium 238 would mean increasing reliance on plutonium with all the environmental and proliferation problems associated with it. Transition to thorium fuel and MSTR would remove most objections to nuclear power and make it an acceptable and economic addition to renewable and other long term energy sources. The choice between FBR and MSTR is the choice between plutonium technology and thorium technology. Plutonium 239 is notorious by its military use, much more than its thorium technology fissile counterpart U233.

As for the fissile materials management, in case of adoption of large scale FBR technology, we should not overlook very complex safety problems associated with the need of safe storage, transport of annual supply of fissile material to many hundreds or even thousand of FBR in many old and new nuclear countries. It is difficult to contemplate the future where reactors numbering over thousand and using thousands tons of plutonium would be installed and operated in a 
wide range of countries without absolutely efficient and fail proof international controls and inspection system.

\section{Starting Requirements for Introduction of FBR and MSTR Respectively}

To understand the quantitative relationships of preceding and unavoidable plutonium producing phase, we look at the specific example of CPP replacement strategy with operation of LWR reactors until 2065 and with introduction of FBR reactors in the period 2065-2105. To be specific and quantitative we use the figures from the proposed strategy to replace all CPP with nuclear power plants [1]. In order to quantify the mass of plutonium necessary to start FBR energy production we used the design data from Super-Phoenix, i.e. the quantity of $6.5 \mathrm{t}$ of plutonium per GW, covering initial charges and first annual replenishments. The Super-Phoenix data are used with caution, since they are likely to be optimistic on plutonium production, especially as the later developments of FBR reactors may have different coolants. For the task of replacing 2,100 GW of LWR with FBR in the course of 40 years from 2065-2105, the quantity of reactor grade plutonium amounting to $13,650 \mathrm{t}$ would be required. Continuing with the example of CPP replacing strategy, plutonium production from 2016, through the period of coal plants replacement with nuclear power in the years 2025-2065, and the period from 2065-2105, when all the LWR reactors with a 40 years lifetime would retire, would reach a total of $15,390 \mathrm{t}$. If we assume the 60 years lifetime for outgoing LWR plutonium production until 2125 would be 22,015 t. Both of these plutonium productions would cover the continuation of operation on the level of 2,100 GW of FBR of the Super-Phoenix characteristics. Total uranium consumption from 2016-2105 would reach $15.39 \mathrm{Mt}$, assuming 40 years of operating life for LWR reactors. For extended working life of outgoing LWR, last one ending operation by 2125 , cumulative uranium consumption would reach $22.02 \mathrm{Mt}$. These figures are less than 26.5 $\mathrm{Mt}$, the estimate for the total amount of uranium recoverable until the end of this century at still tolerable price of $140 \mathrm{USD} / \mathrm{kg}$ U. There should be little doubt that in the years 2065-2125 this much uranium could be found [14] and we assume the availability of this higher figure for plutonium production. Retiring of LWR reactors, built in the replacement period from 2025-65 before the working life of the last one expired by 2105 , would not be economical unless they could be replaced with some cheaper carbon free energy source. The economy would dictate their operation until the end of working life, nominally 40 years. In case of extended working life of 60 years operations would end by 2125 .

For the case of introducing MSTR a considerable amount of fissile material is necessary. As the starting fissile material, U233, is not present in nature, plutonium produced in nuclear build-up from 2025-2065 can be used instead. We give some figures in order to judge relationships. To stay with specific numerical example of CPP replacement in a transition time of 40 years ending 2065, 15,390 t of plutonium would be produced in the years 2016-2105, or 22,020 t of plutonium would be produced in the years 2016-2125 for extended life of LWR plants. If we use a figure of $7.46 \mathrm{t}$ of plutonium per GW [14] to start thorium reactor with plutonium, the amount of plutonium obtained from LWR with working life of 40 years would start 2,063 GW of MSTR. With LWR reactors working life of 60 years 2,952 GW of MSTR could be started. We can conclude that initial charge would not be a limitation to continue MSTR on the same power level of prior operation of plutonium producing LWR reactors, which is $2,100 \mathrm{GW}$.

According to Ref. [14], annual breeding yield for thorium core reactor is $95 \mathrm{~kg}$ of $\mathrm{U} 233$ for 1,500 MW, or $63.3 \mathrm{~kg}$ of $\mathrm{U} 233$ per GW annually. With initial inventory of $3,260 \mathrm{~kg}$ of U233 per GW, one would need to operate thorium core reactor for 51.5 years to breed initial inventory to launch the next generation of 
MSTR reactors. With linear build-up during the years, 2065-2105, breeding in 2,100 GW of MSTR would produce amount of $\mathrm{U} 233$ sufficient to launch $815 \mathrm{GW}$ of additional MSTR.

\section{Foreseeable Future Uranium Resources and the Transition to Thorium Energy}

A discussion on the future availability of uranium is given in Ref. [4]. We give a short summary. In the "Red Book" on nuclear fuel resources estimates are obtained simply by collecting data on conventional resources from IAEA countries. Many countries are lightly explored in uranium and many countries do not report resources in all categories so there are almost certainly large quantities of uranium that are not yet included in "Red Book". Therefore, the "Red Book" estimates of uranium resources should be considered a today's lower bound on the amount of uranium likely to be recoverable.

For analysis of uranium resources after 2065 it is necessary to estimate the amount of uranium that will ultimately prove to be economically recoverable. This amount is defined as "total recoverable uranium resources". It depends on geologic parameters, as well as on development in technologies of exploration, extraction, and use. The total recoverable uranium resources could be determined from first principles by summarizing estimates of the abundance of uranium in the crust of the earth as a function of concentration and accessibility. Geologic data indicate that the total amount of uranium increases exponentially with decreasing ore grade. Synthesizing the power law for total amount of uranium and assumption that the cost of extracting a unit mass of uranium varies linearly with the inverse of the ore grade, one obtains a simple crustal model,

$$
\frac{Q}{Q_{0}}=\left(\frac{P}{P_{0}}\right)^{\varepsilon}
$$

where,

$Q=$ quantity $(\mathrm{Mt} \mathrm{U})$ of uranium available at the price level $P(\mathrm{USD} / \mathrm{kg} \mathrm{U})$;
$Q_{0}=$ quantity of uranium available at some reference price $P_{0}$;

$\varepsilon=$ long term elasticity of uranium supply.

This model must be calibrated through the selection of a reference point $\left(P_{0}, Q_{0}\right)$ and the estimation of $\varepsilon$.

The "Red Book" data could be used as a reasonable point of departure for extrapolation of total recoverable uranium resources estimates. Therefore, the uranium resources quantity of $0.796 \mathrm{Mt} \mathrm{U}$ available at price 40 $\mathrm{USD} / \mathrm{kg} \mathrm{U}$ has been selected as the reference point. The long term elasticity of uranium supply, $\varepsilon$, is estimated by different groups [15] and its values range from 2.35 to 3.5. In our estimation of total recoverable uranium resources we have used $\varepsilon=2.8$, the value from the middle of the given range. Using the selected reference point and $\varepsilon=2.8$ value, total recoverable uranium resources are calculated by simple crustal model for different cost ranges. The calculated values range from $5.5 \mathrm{Mt} \mathrm{U}$ for cost category of $80 \mathrm{USD} / \mathrm{kg} \mathrm{U}$ to almost $150 \mathrm{Mt} \mathrm{U}$ for cost category of $260 \mathrm{USD} / \mathrm{kg} \mathrm{U}$. The estimate of the total amount of uranium recoverable at still tolerable price of $140 \mathrm{USD} / \mathrm{kg} \mathrm{U}$ is $26.5 \mathrm{Mt} \mathrm{U}$.

Based on estimates obtained by simple crustal model, we assumed that the total amount of uranium recoverable until the end of this century at still tolerable price of $140 \mathrm{USD} / \mathrm{kg} \mathrm{U}$ is $26.5 \mathrm{Mt}$. Somewhat speculative estimates like these require a dose of optimism. In case they should prove wrong, our remaining hope is the sea uranium, unlimited quantity, at a price. Against this perspective, or rather additional to it, we now have a renewed perspective of MSTR, with considerable less uranium requirements in initial phase and none afterwards.

Thorium is a metal found in small quantities in most rocks and soils. Its global crustal abundance in the earth's crust is between three and five times that of uranium. According to the most recent edition of the Red Book [16] worldwide identified thorium resources amount 6.4 Mt. The annual production of thorium, recovered as by-product from active mines, is estimated to $90,000 \mathrm{t}$ [17]. 


\section{Summary and Discussion}

Following these estimates on total uranium and thorium resources we give some comments on the long term future of fission energy. Should fission energy be required after 2065, due to one or more causes, such as delay in fusion energy or CCS development, inadequate capacities of wind and solar energy, the need to cover the base energy consumption, or unexpected consumption increase due to climate change, several strategies would be available. Two nuclear fission technologies have a potential to produce large amounts of carbon free energy for centuries. One would be burning U238 in FBR reactors; another would be burning Th232 in MSTR reactors. Essential consideration in both of these technologies is the initial fissile material to start reactor operation as neither U238 nor Th232 are fissile nuclides. Without initial fissile material long term large scale production of fission energy is not possible. Following the example of proposed initial LWR line from 2025-2065 [1] available starter nuclide would be plutonium produced in LWR reactor operation in the nuclear build-up from 2025-2065 and in the transition period 2065-2105, respectively 2065-2125 for extended life of LWR reactors. Only practically available starter fissile material for MSTR reactors would also be plutonium from operation of thermal fission reactors, before it can be replaced by U233 from operation of MSTR reactors. Selection of uranium-plutonium reactor technology, on the other hand, would require frequent extraction and recharging of plutonium fuel during the entire operation time of fast reactors, as the unavoidable part of reactor operation. This difference would be an advantage of MSTR technology as it would limit proliferation sensitive operations to 40 or 60 years transition period. In the choice between FBR and MSTR reactors, additional to superior proliferation safety of MSTR reactors, one should note the safety advantages of liquid fuel, free of fuel radiation damage problems associated with solid fuel. Important advantage of liquid fuel is possibility of the on line extraction of fission products which act as neutron absorbers. Transition to thorium fuel which burns with high utilization, would ensure availability of fission energy for almost any foreseeable time whilst avoiding large and long term production and use of plutonium. By operation of LWR reactors in the years 2025-2065 fissile material would be accumulated opening the possibility to use $\mathrm{U} 238$ or Th232 to produce practically unlimited amount of carbon free energy. Recognition of advantages of MSTR technology and joint development efforts of Chinese, American and other world scientists offer the road and the hope for a timely and achievable nuclear solution of climate problems. LWR initiated MSTR strategy can offer us long term carbon free energy future with considerable advantages in nuclear and proliferation safety.

Proposed example of LWR strategy of replacement of coal power plants in period 2025-2065 and the exiting LWR plants operation from 2065-2105, or 2065-2125 in case reactors lifetime of 60 years, would produce enough plutonium, 15,390 t respectively $22,015 \mathrm{t}$, to supply starting charges to continue production of nuclear power with thorium cores after 2065 at not lower level than 2,100 GW after 2065. Using the MSTR reactor figures from Ref. [12] for the thorium inventory of 68.1 ton per GW and annual thorium feed rate of $1 \mathrm{t}$ per $\mathrm{GW}$, the amount of thorium required for deployment and operation of MSTR reactors in the period 2065-2105 would amount $185,000 \mathrm{t}$. This amount of thorium could be produced in less than three years as the by-product coming from titanium mines alone. Breeding properties of MSTR reactors would in the years afterwards allow expansion of power if needed. Whether we plan to use or not the nuclear fission energy on the large scale in future, the option should be preserved. It would be preserved in plutonium produced by operation of LWR replacing the CPP. It would not be responsible to loose the option.

After this attractive perspective, a word of caution. LWR-MSTR technology is, as far as can be judged at 
present, a promising one. However, the need of reprocessing of large quantities of spent fuel for starting charges, even at essentially smaller quantities than in the case of FBR reactors, would require international inspection system warranting full safety in all phases of manipulation, transport and use of proliferation sensitive materials.

\section{Conclusions}

Uranium fuel has limited capacity on global energy consumption scale when burnt in thermal reactors. Our recent climate relevant proposal [1] of replacement of all coal power plants with now available proven reactors (advanced LWR reactors) in the period 2025-2065 would replace coal power plants with 1,600 $\mathrm{GW}$ of nuclear power in 40 years, in total $2,100 \mathrm{GW}$ assuming operation of $500 \mathrm{GW}$ of nuclear power by 2025. Carbon emission annual reduction would reach 11.84 Gt by 2065 . This significant contribution would be also useful to provide base energy production independent of intermittent sources. Uranium consumption for this replacement strategy would be 15.4 Mt for reactor operation time of 40 years, and 22.0 $\mathrm{Mt}$ for 60 years operation life. Hopefully, this could be covered with future resources discoveries, but clearly, future long term use of fissile energy must use uranium much more efficiently. Secondly, not immediately available nuclear fission technologies, have a potential to produce large amounts of carbon free energy for many centuries. One would be burning U238 in FBR reactors; another would be burning Th232 in MSTR reactors. Essential consideration in both of these technologies is the initial fissile material to start reactor operation as neither U238 nor Th232 are fissile nuclides. Without initial fissile material long term large scale production of fission energy is not possible. Nuclear properties of U238 and Th232 are such that plutonium from thermal reactors can be used as initial fissile material in FBR and MSTR reactors. After the operation of LWR reactors linearly replacing CPP in the years 2025-2065 and operating until the end of working life of 40 or 60 years the amount of produced plutonium would launch about the same power as preceding LWR reactors, offering the possibility to continue operation with FBR reactors or MSTR reactors, consuming U238, respectively Th232. Comparing these two technologies with unequal development status where weak points of FBR are visible, and experience with MSTR is limited, any definite judgement on two technologies would be premature. But, as far it can be judged at present, MSTR should be preferred choice on many points such as reactor and proliferation safety, and abundance of thorium.

\section{References}

[1] Knapp, V., Matijević, M., Pevec, D., and Lale, D. 2016. "Carbon Emission Impact for Energy Strategy in which All Non-CCS Coal Power Plants Are Replaced by Nuclear Power Plants." In Proceedings of the 11th International Conference of the Croatian Nuclear Society 87: 1-10.

[2] Knapp, V., Pevec, D., and Matijevic, M. 2010. "The Potential of Fission Nuclear Power in Resolving Global Climate Change under the Constraints of Nuclear Fuel Resources and Once-Through Fuel Cycles." Energy Policy 38 (11): 6793-803.

[3] OECD/NEA-IAEA. 2008. Uranium 2007: Resources, Production and Demand. Organization for Economic Co-operation and Development/Nuclear Energy Agency-International Atomic Energy Agency.

[4] Pevec, D., Knapp, V., and Trontl, K. 2012. "Long Term Sustainability of Nuclear Fuel Resources." In Advances in Nuclear Fuel, edited by Revankar, S. T. Croatia: InTech.

[5] IAEA TECDOC 1691. 2012. Status of Fast Reactor Research and Technical Development.

[6] National Nuclear Laboratory. 2012. Comparison of Thorium and Uranium Fuel Cycles. Report prepared for and on behalf of Department of Energy and Climate Change.

[7] Energy Process Developments, Ltd. 2015. Feasibility of Developing a Pilot Scale Molten Salt Reactor in the UK.

[8] Hesketh, K., and Thomas, M. 2013. "The Potential Role of the Thorium Fuel Cycle in Reducing the Radiotoxicity of Long-Lived Waste." In Proceedings of the Waste Management Conference: International Collaboration and Continuous Improvement, Paper 13477.1-9.

[9] Krahn, S., Croff, A., Ault, T., and Wymer, R. 2013. "Why Reconsider the Thorium Fuel Cycle?" In Proceedings of GLOBAL International Nuclear Fuel Cycle Conference-Nuclear Energy at a Crossroads, 367-81. 
[10] Croff, A. G., and Krahn, S. L. 2016. "Comparative Assessment of Thorium Fuel Cycle Radiotoxicity." Nuclear Technology 194 (2): 271-80.

[11] 1971. Molten-Salt Reactor Program. Oak Ridge National Laboratory report, ORNL-4728.

[12] Gehin, J. C., and Powers, J. J. 2016. "Liquid Fuel Molten Salt Reactors for Thorium Utilization." Nuclear Technology 194 (2): 152-61.

[13] The Weinberg Foundation. 2013. Thorium-Fuelled Molten Salt Reactor. Report for the All Party Parliamentary Group on Thorium Energy.

[14] Heuer, D., Merle-Lucotte, E., Alibert, M., Brovchenko, M., Gheta, V., and Rubiolo, P. 2014. "Towards the Thorium
Fuel Cycle with Molten Salt Fast Reactors." Annals of Nuclear Energy 64 (February): 421-9.

[15] Schneider, E. A., and Sailor, W. C. 2008. "Long-Term Uranium Supply Estimates." Nuclear Technology 162 (3): 379-87.

[16] OECD/NEA-IAEA. 2014. Uranium 2014: Resources, Production and Demand. Organization for Economic Cooperation and Development/Nuclear Energy Agency-International Atomic Energy Agency.

[17] Ault, T., Gossen, B. V., Krahn, S. L., and Croff, A. G. 2016. "Natural Thorium Resources and Recovery: Options and Impacts." Nuclear Technology 194 (2): 136-51. 